Mientras varios países latinoamericanos eran sacudidos por las dictaduras de los setenta, el estado democrático venezolano gozaba de la mayor bonanza económica de su historia. La nacionalización del petróleo y una coyuntura de mercado favorable fueron los detonantes principales de esta nueva situación que desembocó, irónicamente, en el endeudamiento más grande que ha conocido el país, en el enriquecimiento de pocos y en el bienestar muy relativo de muchos. Durante esa década el estado no escatimó esfuerzos ni inversiones en el área cultural: son los años dorados de Monte Ávila Editores y del Centro de Estudios Latino-americanos Rómulo Gallegos. El fenómeno del exilio en el cono sur, por otra parte, llevó a Venezuela un buen grupo de intelectuales que durante años influyeron muy positivamente el ambiente cultural, la investigación y las artes.

Durante los setenta se perpetúa una generación de poetas que es comúnmente asociada al nacimiento de la democracia (1958): las dos líneas de trabajo esenciales de este período son las que desarrollaron Ramón Palomares - El reino (1958), Honras fúnebres (1962), Paisano (1964), Santiago de León de Caracas (1967), El viento suave del amanecer con los primeros aromas (1969), Adiós Escuque (1974) Poesía (obra completa, 1977)- y Rafael Cadenas - Cantos iniciales (1946), Los cuadernos del destierro (1960), Falsas maniobras (1966), Memorial (1977), Intemperie (1977) Amante (1983); ambos son considerados, aún entre las más recientes promociones de lectores y poetas, como fundamentales. Además de ellos, otros poetas que comenzaron su producción en los sesenta desarrollaron y ampliaron su obra: Ida Gramcko, Juan Sánchez Peláez, Alfredo Silva Estrada, Ana Enriqueta Terán, Elizabeth Schön, Hesnor Rivera, Rafael José Muñoz, Francisco Pérez Perdomo, Juan Calzadilla, Guillermo Sucre, Darío Lancini, Caupolicán Ovalles, Ludovico Silva, entre otros. Si bien la producción de ellos es de notable interés y se prolonga, en algunos casos, hasta nuestros días, he preferido hacer un corte para revisar las tendencias dominantes que surgen a partir del setenta y que contienen, de modo residual, una buena parte de las dominantes de la década previa.

Sin la utópica intención de ser exhaustivo, supongo conveniente hacer algunas anotaciones en torno al fenómeno de la poesía en Venezuela a un nivel bastante general. En este sentido, un dato que resulta curioso es que un buen número de los poetas del período realizó, o realiza, estudios académicos y/o dicta clases en la universidad. ${ }^{1}$ No pretendo

${ }^{1}$ Ida Gramcko, Hesnor Rivera, Francisco Pérez Perdomo, Rafael Cadenas, Guillermo Sucre, Alfredo Silva Estrada, José Barroeta, Blas Perozo Naveda, Reynaldo Pérez-So, Hanni Ossot, Márgara 
establecer una relación mecánica entre la vida y la obra de estos autores, pero creo que se puede decir que ese dato no es irrelevante, sobre todo si se tiene en cuenta que el espacio académico (su poder, sus influencias) es breve y produce un tipo de conocimiento muy particular. El fenómeno de la poesía en Venezuela, entonces, está ligado, en gran medida, a la academia, entendida ésta como espacio de divergencias problemáticas y, a la vez, como lugar relativamente privilegiado en cuanto a información cultural se refiere. Un estudio minucioso que persiga la reelaboración de discursos intelectuales de la academia europea y norteamericana; sobre todo en la poesía venezolana reciente puede dar cuenta de un interesante proceso de apropiación que a fin de cuentas, podría ser característico del fenómeno. Si se considera, por otro lado, la producción poética como una práctica discursiva que involucra mucho más que el simple resultado -el poema - entonces habría otra línea de trabajo que ofrece mucho interés: el rastreo de las razones que llevan al poeta (al escritor) a introducirse en el mundo académico (¿búsqueda de legitimación, alternativa laboral?). Otra observación que se puede constatar es que la mayoría de los poetas que publican en Venezuela son hombres; si bien es cierto que el porcentaje de mujeres con respecto a momentos anteriores (por ejemplo en antologías previas ${ }^{2}$ ha aumentado considerablemente). No es momento de revisar una problemática de larguísimo catálogo, como la de la mujer; por ahora basta señalar que en el espacio de la poesía venezolana se reproduce y se hace visible esa problemática, a pesar de que tiende a "resolverse", por lo menos en términos cuantitativos.

Las editoriales que se han ocupado, entre otras labores, de publicar poesía en Venezuela son fundamentalmente dos: Monte Ávila y Fundarte, ambas funcionan con financiamiento del estado. Paralelamente existe un archipiélago de pequeñas editoriales que funcionan con financiamiento privado (en muchos casos proveniente de los mismos autores): entre ellas Angria y Pequeña Venecia. ${ }^{3}$ En todo caso los tirajes se mantienen en cifras bajas (entre 500 y 1.000 ejemplares), lo cual hace pensar que la poesía, a pesar de tratarse de un fenómeno de escasa difusión, recibe un apoyo fuerte, aun en medio de la situación crítica que atraviesa Venezuela. ${ }^{4}$ Una estrategia alternativa de publicación,

Russotto, Alejandro Oliveros, Armando Rojas Guardia, Manuel Hernández, Yolanda Pantin, Miguel Márquez, María Auxiliadora Álvarez, Rafael Castillo Zapata, Rafael Arráiz Lucca, Alberto Barrera, entre otros.

${ }^{2}$ En la Antología venezolana (Verso) de José Ramón Medina (1962), por ejemplo, se incluyen cincuenta hombres y apenas siete mujeres, cubriendo un período que se inicia con la generación del 1918 y termina en el año 1946. Mientras que Javier Lasarte en Cuarenta poetas se balancean; poesía venezolana 1967-1990; antología (1991) incluye 28 hombres y 12 mujeres.

${ }^{3}$ Algunos ejemplos de publicaciones de estas editoriales son: El diario de John Roberson (1990), de Blanca Strepponi; El arte de la pérdida (1991), de Verónica Jaffé; La canción fría (1989), de Yolanda Pantin.

${ }^{4}$ En un país que ha sufrido dos intentos de golpe de estado en 1992, donde un magnífico número de discos vendidos por algún grupo de rock local es tan sólo 15.000 , donde un libro es best seller si alcanza los 3.000 ejemplares vendidos, donde las distribuidoras y librerías traen del exterior textos especializados por encargo y no especializados por cuentagotas, no resulta raro que la poesía esté entre los worst-sellers. Cómo no pensar en la escasa repercusión cultural que tiene la poesía en el público - en lo vano de cualquier intento de periodizarla - cómo no pensar que otros fenómenos, como la música, la telenovela o el arte, ocupan espacios mayores y funcionan más efectivamente en sociedad. 
además de la que brindan algunas revistas, ${ }^{5}$ la ofrecen los concursos de poesía, que abundan de tal manera que casi todo poeta cuenta en su curriculum con alguna presea y su consecuente edición. ${ }^{6}$

\section{Los setenta}

Pareciera inevitable tener que hacer unas notas sobre los años sesenta antes de entrar en materia, a pesar de que puedan resultar prescindibles para el lector avisado. La década del sesenta acumula una serie de hechos históricos y estéticos que aun los que fuimos niños en aquel momento conocemos de memoria, gracias a un sinnúmero de representaciones (cinematográficas, literarias, plásticas), que con obstinante insistencia dan cuenta del período, o por lo menos de lo que se piensa que éste fue. Este no es el lugar para revisar todas esas nociones, baste con decir que su confluencia aún es notable en nuestros días: la generación que surge en ese momento es, en muchos casos, la que dirige las políticas culturales del Estado, de fundaciones privadas y otras formas de asociación cultural. Para hacer corto un cuento largo se puede decir que los planteamientos poéticos se desarrollaron en relación a $\longrightarrow$ en conflicto con- un espacio ideológico problemático y fuertemente esperanzador para el futuro del país: es el período donde se pone a prueba la democracia recién nacida; la guerrilla, por su lado, se hace fuerte contra ella, bajo la consigna de que ésta no era realmente lo que se esperaba, sino una nueva máscara del poder de pocos y del interés transnacional. Los sectores intelectuales se ligaron, a su manera, a esa protesta social. ${ }^{7} \mathrm{En}$ la Universidad Central de Venezuela, por ejemplo, se realizó una renovación del sistema educativo que "modernizó" (para bien o para mal) las nociones "europeizantes" de la vieja guardia pedagógica. La Escuela de Letras de esta universidad (donde muchos de los poetas que me interesan se graduaron y donde hoy en día dan clases) liderizó, en parte, tal movimiento. El techo de la ballena ${ }^{8}$ se opuso con vigor a la retórica del "costumbrismo", al "localismo realista" que permanecía como tendencia hegemónica en la perpetuación de modelos de escritura al estilo de Rómulo Gallegos. La poesía que se escribió durante ese período exploró los espacios de la modernidad cosmopolita alejándose de las temáticas nacionales ${ }^{9}$ y asumiendo la tradición europea de la vanguardia. Durante ese momento es

${ }^{5}$ Cultura Universitaria, En Ancas, Falso Cuaderno, Hojas de Calicanto, Imagen, La Gaveta Ilustrada, Lamigal, Papel Literario de 'El Nacional', Papeles, Poesia, Actual, Revista Nacional de Cultura, Suplemento Cultural del Diario Últimas Noticias, Zona Franca, La Oruga Luminosa, Zona Tórrida, etc.

${ }^{6}$ Algunos de los concursos de poesía que se realizan o realizaron en Venezuela son: Premio Consejo Nacional de la Cultura; Premio Municipal (D.F.) de Literatura; Premio Municipal de Literatura Manuel Díaz Rodríguez; Premio Fernando Paz Castillo; Bienal de Literatura José Rafael Pocaterra; Concurso Literario "Casa de la Cultura de Maracay".

${ }^{7}$ Un estudio abarcador, profundo y plural de las modulaciones político-culturales de Venezuela durante aquellos años es recopilado por Alfredo Chacón: La izquierda cultural venezolana (19581968).

${ }^{8}$ Grupo que alojó poetas y artistas con propuestas fuertemente vanguardistas y radicales en contra de las formas burguesas de arte y literatura.

${ }^{9}$ Un caso interesante y esencial que no se adecúa a tal experiencia es el de Ramón Palomares, quien desarrolla una poesía ligada al telurismo y a un nuevo lenguaje, sin la cual no se puede pensar la poesía venezolana del momento. 
cuando “... la poesía de tema nacional ... se transforma para, desde la perspectiva del nuevo mundo urbano, cantar la pérdida de la región interior, apropiándose de ópticas, motivos, léxico y fórmulas sintácticas características de los discursos de ese ámbito". ${ }^{10} \mathrm{El}$ establecimiento más o menos firme de la temática metropolitana en la poesía de esos años se convirtió, con el tiempo, en una fuerte dominante en algunos poetas de los setenta y de los ochenta, transformándose, incluso, en una retórica.

La experiencia poética de los sesenta (Rafael Cadenas, Ramón Palomares, Juan Sánchez Peláez, Francisco Pérez Perdomo, José Barroeta, Arnaldo Acosta Bello, etc.) se puede centrar, un tanto ajustadamente, en la exploración de la problemática del yo ante el mundo. Esta dominante permanece en las décadas siguientes, reajustada a nuevas expectativas y situaciones; mientras que la onda militante de alguna poesía del sesenta ${ }^{11}$ pierde fuerza en los setenta, o permanece como poética de pocos (Víctor Valera Mora, William Osuna). De hecho, muchos de los poetas de los sesenta son, para Vilma Vargas, "testigos de su época", mientras que otros no, como Pérez Perdomo, quien "parece mantenerse dentro de aquella poesía esencial que sólo se enfrenta al destino universal del hombre, línea poética que se mantendrá hasta hoy". ${ }^{12}$ Javier Lasarte nota que hacia finales de los sesenta y comienzos de los setenta se conforman algunas líneas de trabajo que serían las dominantes durante la segunda década. Estas líneas se sugieren en los libros Elegos, de Eugenio Montejo (1967), Si el verano es dilatado (1968), de Luis Alberto Crespo, Todos han muerto, de José Barroeta (1971), Amaneci de bala, de Víctor Valera Mora (1971). ${ }^{13}$

\footnotetext{
${ }^{10}$ Lasarte 5-6.

"Un poema comúnmente considerado como paradigmático de esta onda es "Derrota", de Rafael Cadenas, donde se asume la pérdida que sufriera la guerrilla en años posteriores, o una pérdida más abarcadora: la de la generación del sesenta.

${ }^{12}$ Vargas 77.

${ }^{13}$ Los poetas nombrados por Lasarte como figuras que establecen, de alguna manera, los lineamientos principales de la década del setenta, conforman un dibujo interesante. Valera Mora, por ejemplo, publicó además de Amanecí..., Con un pie en el estribo (1972), 70 poemas estalinistas (1979) durante esta década. Sus obras se mantuvieron entre dos polos fundamentales y no exclusivos: el político y el amoroso, manteniendo siempre un carácter irreverente, urbano. "La mayor parte de los textos del Chino Valera Mora están elaborados en base al habla, y no sólo eso: en base a una tradición histórica que toma en cuenta al habla para las distintas transformaciones sociales; el estado más elevado de estas serían las revoluciones o, para conjugar: en la revolución": Jiménez (prólogo de Victor Valera Mora. Antología). La poética de Eugenio Montejo es otra: Lasarte nota que: "su trabajo no es ajeno al uso de modos y formas poéticas tradicionales - la rima ocasional, el trabajo persistente sobre el ritmoni a la voluntad de hacer de la versificación un medio para el decir comunicativo, ni a la imagen que se construye a partir de paisajes descriptivos o narrativos, ni a la presencia de temas que se quieren trascendentes - comunidad e individuo, mundo y palabra, el poeta y el poema como vaso comunicante": Lasarte 9. Montejo continúa escribiendo una obra interesante, reflexiva fundamental. Sobre los poemas de Luis Alberto Crespo, José Balza piensa que "exponen una experiencia que ocurre en el seco aire libre (fugaz, vertiginoso: hiriente y tierno)". O bajo cierta casa resonante, melancólica y "suelta". Pero ambas metáforas escudan otra - más perturbadora: un territorio común a nosotros, definido así por el autor: En qué muerte estamos/qué país es éste que nos tapa. Es decir: la resolana del desierto (o de la abundancia), de lo perdido (y sin embargo persistente): el fogonazo que ya manchó a Reverón: Venezuela Salas. Antología 241. Salvador Garmendia plantea que la poesía de José Barroeta
} 
Este último libro estableció una de las vertientes que haría eclosión a principios de los ochenta, caracterizada por la retórica de lo cotidiano, el discurso amoroso cercano al bolero y al lenguaje coloquial expresado con soltura en una poesía de franco carácter político y conversacional. La cercanía de su poesía al panfleto político, al poema revolucionario, así como su otra temática fuerte - la amorosa - son antecedentes claros de la poesía de los grupos Tráfico y Guaire (81-82). En Eugenio Montejo, por otro lado, es notable una producción más vinculada a la tradición europea; se trata de una poesía reflexiva y muy elaborada que permanecerá como una firme dominante en los setenta. Guillermo Sucre plantea que la poesía de Montejo se mueve entre dos polos: "La nostalgia de lo cósmico e inmemorial y la desacralización del presente...". ${ }^{14}$ Aun en sus libros más recientes (Trópico absoluto, 1982 y Alfabeto del mundo, 1987) mantiene esa reflexión inteligente que lo configura, probablemente, como uno de los poetas más leídos y estudiados. Otro poeta representativo del momento es Luis Alberto Crespo, quien propone un reflexión vinculada de cierta manera al telurismo (su antecedente más cercano es Ramón Palomares), pero con un acento fuertemente marcado en la interioridad; es notable cierta noción esencialista que entiende al poema como espacio de brevedad y pureza, y al paisaje como camino hacia la interioridad. Esta concepción (común a varios de los poetas de los setenta) establece un corte bastante visible con respecto a la generación que surge a principios de los ochenta: ellos entenderían al paisaje (primordialmente urbano) como espacio natural de la poesía y no como camino a ninguna parte. La producción de Luis Alberto Crespo está vinculada a lo que se llamó la poesía breve, que será, a lo largo de los setenta, la dominante más fuerte. En una entrevista con Rafael Arráiz Lucca, él mismo plantea que "quisiera escribir una poesía que no le pusiera tantos adjetivos trágicos a las cosas". ${ }^{15}$

La década del setenta coincide con una doble variante del espacio cultural: por un lado pierden fuerza los proyectos políticos alternativos y por otra se produce una gran apertura del espacio institucional para la cultura, producto, probablemente, de la avalancha de dólares que recibió el estado y de una gerencia cultural bastante dispuesta a invertir en el área. En los setenta nos encontramos con:

una sociedad que excepcionalmente disfruta de una bonanza económica, a cuyo amparo lacultura encuentraespacios institucionales en expansión. Buenaparte de la intelectualidad venezolana se integra a ese circuito que ofrece, en el caso específico de la poesía, becas y bolsas de trabajo para escritores; editoriales que, como Monte Ávila o Fundarte, abren sus puertas ...; y una proliferación de talleres y concursos de poesía. ${ }^{16}$

El momento significó un cambo radical con respecto al previo: de la vida al margen del espacio contestatario, el poeta se desplazó a un lugar central institucionalizado.

\footnotetext{
"discurre siempre en un tono elevado, que se nutre de emociones primarias y definitivas, rondando siempre los estratos más seguros de la memoria: la infancia, los afectos, las primeras casas": Salas, Antología 245.

${ }^{14}$ Sucre 310.

${ }^{15}$ Arráiz Lucca. Grabados 179.

${ }^{16}$ Lasarte 8.
} 
La creación bastante definitiva de un espacio separado para la poesía, en el sentido que propusiera la modernidad, define otro corte con respecto a la poesía de los ochenta. Los poetas del setenta orientaron su trabajo hacia la "creación", pretendida como independiente de la historia y asociada al universo interior individual. Uno de los grupos de mayor figuración fue el de Valencia, integrado por Eugenio Montejo, Reynaldo Pérez-So, Teófilo Tortolero, J. M. Villarroel París, Rafael Humberto Ramos Giugni, Gabriel De Santis y Alejandro Oliveros. Ligados a las revistas Poesia y Zona Tórrida, ese grupo marca una de las rupturas más interesantes con respecto al período anterior al proponerse, en líneas generales, una poesía deslastrada del peso político que pesaba sobre poetas anteriores y asociada a lineamientos más personales.

La obra de poetas que ya habían publicado en los sesenta también se vio afectada por una reformulación: Rafael Cadenas, Juan Calzadilla, Guillermo Sucre, Eduardo Zambrano Colmenares, Gustavo Pereira, Elena Vera, Alfredo Chacón y Alfredo Silva Estrada, ${ }^{17}$ recurrieron a esa poética de la brevedad, o más bien del silencio esencialista. Javier Lasarte ubica el comienzo de esta dominante, que congregaría un largo número de poetas, ${ }^{18}$ en la poesía de Reynaldo Peréz-So: el inicio, o el paradigma de esta poética, estaría marcado por su libro Para morirnos de otro sueño (1970). "A él se unen cuatro años más tarde, Porlo que y tiene de ceniza, de Eleazar León, ... Ejercicios para decir lo mismo, de Hanni Ossott, Los viajes del buque fantasma, de Elí Galindo, y Espacios de Alejandro Oliveros". ${ }^{19}$ Si bien esta diferenciación es útil para caracterizar la poesía que dominaría en los setenta, quizá sea más preciso anotar que la producción de estos años tenía algo que ver con nociones existenciales que recurrían a la brevedad como molde o formato del sentimiento, para hacer patente lo absurdo de la experiencia vital, creativa, ciudadana: se trataba de una suerte de esencialismo que intentaba para el poema la persistencia de lo "estrictamente importante": 20 el poema fue concebido como espacio deslastrado de retóricas, como expresión del universo interior privado. A esta experiencia interiorista, que de alguna manera puede estar vinculada al reflujo político provocado por el fracaso de los proyectos políticos alternativos, se le sumaría "el gusto creciente por el orientalismo, por la poesía sucinta Zen, por el hai-ku, por poetas tan precisos y constructivistas como los italianos, encabezados por Ungaretti. La influencia de Alejandra Pizarnik no es desdeñable. Tampoco las enseñanzas de Krishnamurti

\footnotetext{
${ }^{17}$ Lasarte 12.

${ }^{18}$ Lasarte cita a Eleazar León, Luis Alberto Crespo, Jorge Nunes, Enrique Mujica, María Clara Salas, Salvador Tenreiro, Manuel Hernández, Santos López, Edda Armas, Alejandro Salas, José Antonio Yepes Azparren, Maritza Jiménez, Patricia Guzmán, Eduardo Castellanos, Víctor Valera Mora, Julio Miranda, Álvaro Montero, William Osuna, Cecilia Ortiz, Reina Varela, Miguel Márquez, Yolanda Pantin, Antonio Urdaneta: Lasarte 12.

${ }^{19}$ Lasarte 11.

${ }^{20}$ Otra manera de entender el poema breve es la que propone Julio E. Miranda en su hipótesis de trabajo sobre la poesía de Edda Armas: "el poema breve como reacción al intento frustrado de totalización de la poesía anterior; el poema breve como concentración individual ante la clausura de una época y la crisis de su correlato literario - la gesta guerrillera; el poema breve como búsqueda de datos elementales de la existencia - recogimiento cuya culminación daría paso a un potencial reinicio de la expansión; el poema breve como triunfo de la visualidad - y de los sentidos-sobre lo conceptual, postulando un nuevo equilibrio": Miranda, El poema breve 14.
} 
y de otros cultores del silencio interior". ${ }^{21}$ Para ilustrar ese discurso del silencio copio un poema del primer libro de Reynaldo Peréz-So:

\author{
21 \\ el hombre no se parece a la lluvia \\ el hombre camina \\ piensa \\ y se multiplica \\ la lluvia \\ vive arriba \\ y baja y se retorna \\ nosotros hablamos y morimos \\ la lluvia es otra $\cos ^{22}$
}

Guillermo Sucre plantea que la obra de Reynaldo Peréz-So "tiende a excluir de sus recursos todo los que son grandes metáforas e ideas, o aún emociones". ${ }^{23}$ Y no sólo metáforas, ideas y emociones fueron excluidas de la poesía de Reynaldo Peréz-So y de los demás poetas de los setenta; excluyeron también cualquier recurso que no fuera imprescindible, que no fuera fundamental para la expresión. El resultado fue, a grandes rasgos, una poesía muy lavada, casi aséptica, muy quintaesencia, producto de la decantación paciente de los medios expresivos. Estas restricciones impusieron, de alguna manera, una jerarquización de las temáticas poéticas, quedando en lugar privilegiado aquellas que estuvieran involucradas en la representación de la experiencia interior, de la reflexión vital. El poeta mantuvo su mirada hacia su universo espiritual, hacia sus carencias y limitaciones; el lenguaje usado, en muchos casos, parecía definirse como un gesto mágico que pretendía ser reacción de ese universo interior, de esa realidad aparte. La palabra se detuvo también, podría decir, sobre sí misma y se despojó de intenciones "no poéticas": esencialismo y textualismo son comunes nociones que se usaron para caracterizar la poesía del momento.

Paralelamente a esta dominante es posible rastrear algunas disidencias claras (Enrique Hernández D' Jesús, Víctor Valera Mora, José Barroeta, William Osuna), pero pareciera inevitable notar la prevalencia de un tipo de poesía breve y esencialista que llevó al poema hasta espacios insólitos, desconocidos y delirantes de la interioridad del poeta. Esa exploración a menudo tiene que ver con un ejercicio de memoria, o de mera introspección creativa que persigue el encuentro con un mundo virgen de leyes misteriosas y secretas que afloran en el verso. Los poemas de Hanni Ossott y de Eleazar León dan cuenta de esta experiencia que pretendía la creación de mundos artificiales y mágicos. Cierto tono de queja, de desolación, abandono, aislamiento, atraviesa en buena medida esta producción. La experiencia de la realidad es asumida, en líneas generales, con cierta inconformidad y extrañeza.

\footnotetext{
${ }^{21}$ Liscano, Poesía:de 1970 a la actualidad 9.

${ }^{22}$ Pérez-So 49.

${ }^{23}$ Sucre 308.
} 
Otra experiencia poética rastreable en la década, que no está del todo separada de la experiencia lírica de la brevedad, es la que concibió al poema como objeto desplegado en el espacio de la página. Rafael Cadenas fue uno de los primeros en experimentar esta posibilidad en la década del sesenta con su "Dibujos a máquina". En los setenta esta experiencia es asumida por poetas como Alfredo Silva Estrada, Lubio Cardozo, Andrés Athilano y Darío Lancini.

En un importante balance de lo que fue la poesía de la década del setenta, Vilma Vargas plantea que: "nuestra última poesía no es muy innovadora, no parece cambiar la estructura del lenguaje poético, si bien por una parte se intelectualiza, por la otra se encierra en un mundo interior muy individual. El lenguaje recibe un tratamiento de depuración, se es parco con él. ¿Se tiene poco que decir o es que todo un mundo cabe en una sola palabra?"24 Este balance ya acusa una de las quejas que la generación que surge en los ochenta reclama duramente a la del setenta: la parquedad; de hecho, se puede pensar que la poesía del setenta en Venezuela ganó para ésta un espacio liberado de las ataduras políticas, regionalistas o realistas creando un lugar de libertad creativa donde privó lo esencial; pero en el intento perdió de vista, en muchos casos, la necesidad de un piso comunicativo amplio. Eso plantearían los poetas que se afirmaron en la década del ochenta.

\section{Los ochenta}

Comenzando la década se dio una profunda discusión en los medios especializados sobre la problemática de la poesía reciente en Venezuela. De esta discusión, cuyos planteamientos fundamentales fueron recogidos en la revista Zona Franca ${ }^{25}$ surgieron nuevas propuestas y un par de grupos: Tráfico y Guaire, que replantearon el sentido poético del momento. Armando Rojas Guardia, Igor Barreto, Yolanda Pantin, Miguel Márquez, Alberto Márquez, Rafael Castillo Zapata integraron el primer grupo; mientras que Rafael Arráiz Lucca, Luis Pérez Oramas, Javier Lasarte, Nelson Rivera Prato, Leonardo Padrón y Alberto Barrera estuvieron vinculados al segundo. Estos poetas venían o participaban de la experiencia de los talleres, principalmente los que se generaron alrededor del Centro de Estudios Latinoamericanos Rómulo Gallegos y de Calicanto dirigido por la narradora y poeta Antonia Palacios. Esta circunstancia puede haber marcado la permanencia en algunos de ellos (como Miguel Márquez) de poéticas residuales de los sesenta y setenta, como la de la brevedad, y luego, quizá por efecto de rechazo a los "maestros", puede haber detonado la poética urbana, fuertemente conversacional y conectada a la experiencia cotidiana, contraria al esencialismo, ligada a las representaciones tradicionales del amor (el bolero, el tango, la ranchera). Algunos de los libros publicados durante la década que dan cuenta de este replanteamiento son: Correo del corazón, (1985) de Yolanda Pantin, ¿Y si el amor no llega? (1983) de Igor Barreto, Guaire (1982) de Rafael Arráiz Lucca, Nelson Rivera Prato y Armando Coll, Arbol que crece torcido, (1984) de Rafael Castillo Zapata, Yo que supe de la vieja herida (1985), de Armando Rojas Guardia y Díme con quien amas/amor que por demás (1985) de Javier Lasarte y Alberto Barrera.

\footnotetext{
${ }^{24}$ Vargas 10.

${ }^{25}$ Zona Franca 23, II ${ }^{a}$ época (marzo-abril, 1981).
} 
Esta nueva generación nació - o más bien se congregó- con la elaboración de un manifiesto que recoge una profunda y rabiosa queja contra la retórica que se prolonga desde los sesenta hasta comienzos de los ochenta así como un nuevo plan para la poesía venezolana. El párrafo inicial del manifiesto establece claramente ambas pretensiones:

Venimos de la noche y hacia la calle vamos. Queremos oponer a los estereotipos de la poesía nocturna, extraviada en su oficio chamánico de convocar a los fantasmas de la psique o de lanzar hasta la náusea el golpe de dados del lenguaje, una poesía de la higiene solar, dentro de la cual el poeta regrese al mundo de la historia, al universo diurno de la vida concreta de los hombres, en cuyo orbe cotidiano ningún fantasma enfermo moviliza más fuerza que el horror o la belleza encontrable en una acera cualquiera, y ningún aristocrático golpe de dados del verbo podrá abolir jamás el sabor sanguíneo de todas las palabras de la tribu. ${ }^{26}$

Es evidente la identificación de la poesía del sesenta-setenta con la noche y la del ochenta con el día, lo cual hace suponer la asociación de estos términos a una larga cadena de nociones similares que dibujan panoramas de expectativas opuestas: noche: espíritu, psique, oscuridad, misterio, magia, soledad, profundidad; día: claridad, realidad, vida, multitud, comunidad. Según ese manifiesto, la poesía esencialista había llegado al colmo de convertirse un juego estilístico vacío, detenido en las palabras y olvidado de los referentes:

El blanco de sus críticas fue tanto la poética de la brevedad como el poema breve, y sus reivindicaciones se centraban en la incorporación de la experiencia urbana y cotidiana como materia y forma de la poesía, en la recuperación del valor comunicativo del poema y de los recitales como garantía del contacto con el público". ${ }^{27}$

Parte de la furia de Tráfico y Guaire radicaba en la clara obstinación de la moda textualista, según Armando Rojas Guardia.

esta corriente (textualista) surge de los avances más radicales de la poesía de la modernidad y la contaminación literaria de los estudios semiológicos y lingüísticos ... Desde Tráfico se lanzaron obuses contra ese textualismo y en favor de una poesía más emparentada con los postulados de los años cincuenta (Kerouac, Ginsberg, Burroughs, Corso, Ferlinghetti) ${ }^{28}$

Armando Rojas Guardia, quien fuera principal animador de estos postulados, realiza una obra en constante conflicto entre una poética de la calle y una intención religiosa que, aunque resulta francamente anacrónica, se conforma en el discurso más contemporáneo y probablemente de mayor relevancia de la década. ${ }^{29}$

\footnotetext{
${ }^{26}$ Santaella, Diez manifiestos 73.

${ }^{27}$ Lasarte 14.

${ }^{28}$ Yage Jarque 11.

${ }^{29}$ Su poesía interpela sin descanso a la divinidad en una suerte de misticismo post-guerra fría cargado de erotismo: “'La poesía es la instauración del ser por la palabra' escribió Heidegger ... Rojas Guardia no hace más que captar, a través de la poesía, este enunciado del filósofo alemán pero con
} 
Si bien la ciudad como temática poética ya había sido asumida por algunos poetas previos, se puede decir que los grupos Tráfico y Guaire, así como una larga lista de poetas no agrupados, asumieron la ciudad con una noción menos literaria y más vital, hablaron en su idioma, se refirieron a sus personajes y lugares, asumieron como suyos los giros coloquiales y todo lo que implica la experiencia caótica del urbe tercermundista. La nostalgia de un mundo bucólico no es común, lo recurrente es asumir la ciudad como espacio natural de la poesía. A menudo fueron acusados de banales y superficiales; el tiempo y la proliferación de trabajos vinculados a esas propuestas demostró que sus ideas consiguieron terreno fértil entre los jóvenes lectores y poetas. En gran medida abandonaron las referencias cultas que acompañaron a la poesía previa y tomaron para sí los referentes comunes de cualquier ciudadano. Se puede pensar que, en líneas generales, esta poesía se abrió al entendimiento y se acercó a la concepción del poema como lugar de encuentro, como manera de representar y comunicar una experiencia común (el amor, el despecho, la rabia), oponiéndose a las temáticas recurrentes en la poesía previa, a la elaboración de un espacio íntimo, personal, estrictamente poético":

creemos que en poesía no es la rotación de los signos en el texto lo que constituye la clave estética del poema, sino la forma en que accede al oído de los otros la voz de una experiencia humana. Estamos hartos de combinatorias infinitas de palabras que se frotan para arrancarse chispas que no pasan de ser un fuego fatuo ... ${ }^{30}$

El panorama socio-económico de los setenta había permitido, de alguna manera, la creación de amplios espacios para la poesía y la profesionalización del poeta. En los ochenta sobreviene una fuerte crisis económica que reduce tales expectativas. La liberación de la tarifa de cambio del dólar y una cadena de sucesos (inflación, empobrecimiento) son los puntales de la nueva situación. Los poetas salieron de ese espacio profesionalizado, independizado de la historia y del devenir cotidiano volviendo su mirada hacia las estrategias que los podían vincular de nuevo con una realidad cada día más problemática. El giro más notable de esta poesía es visible en su exteriorización radical del sentimiento: los poemas orientan sus referentes hacia la cotidianidad con frescura o patetismo:

características diferentes, entroncadas, desde luego, a un sentimiento religiosos y a una concepción del mundo espiritualizada". Santaella, La lámpara encendida, 108. Este sentimiento religioso que resulta fuera de lugar en medio de una sociedad (la venezolana) supuestamente católica (así como supuestamente democrática); de hecho, la escritura de Armando Rojas Guardia es bastante peculiar en el espectro de la poesía venezolana reciente. Aun así, sus versos transpiran una poderosa contemporaneidad que se hace patente en una fuerte duda que alimenta su fe. No se trata de versos sacros, no se corresponden mecánicamente a las experiencias de los místicos: deshacen su probable anacronismo, al realizarse en un lenguaje y en una experiencia que sólo puede ser de hoy, al detenerse en un sentimiento - el religioso- que persiste aún sin dios. Su versos entrelazan lo cotidiano a lo religioso en un espacio convulso. Además de sus libros de poesía, tiene dos de ensayos El Dios de la interperie y El calidosopio de Hermes, donde, entre otras cosas, se enfrenta al hecho poético, a la experiencia de la fe, al sexo.

${ }^{30}$ Santaella, Diez manifiestos 75. 
... para ellos el compromiso residía en asumir una forma de historicidad, vincularse con la realidad concretísima, con el mismísimo país. Por eso desdeñaron radicalmente mucha de la poesía que los precedía y que incluso los acompañaba, refutaron su herencia, sus propias lecturas y parecían no tolerar otra forma de escritura más válida y eficiente que la propuesta. $^{31}$

Este momento de furia quizá solo corresponde a los inicios de la década: con el paso de ésta se multiplicó el espacio poético dando cabida a una variedad, no registrable aún, de alternativas poéticas. Uno de los aspectos notables del momento es la acumulación de una larga serie de discursos vinculados a la poesía femenina, asociados a una concepción distinta de la experiencia amorosay del cuerpo. Un buen grupo de poetas elaboraron una producción interesante e innovadora, entre ellas son notables los casos de Márgara Russotto, Viola d'amore (1986); Maritza Jiménez, Hago la muerte (1987); Patricia Guzmán, De mí, lo oscuro (1987); María Clara Salas, Linos (1989); Yolanda Pantin, La canción fría (1989) Verónica Jaffé, El arte de la pérdida (1991); Blanca Strepponi, Diario de John Roberson (1990); Miyó Vestrini, Pocas virtudes (1986); Alicia Torres, Fatal (1989); Claudia Noguera, Nada que ver (1989) Jacqueline Goldbergh, Luba (1988); Laura Cracco, Diario de una momia (1989); Edda Armas, Contra el aire (1977) María Vásquez, Guerrero llevado adentro (1987) María Auxiliadora Álvarez, Cuerpo (1985). Este último libro es fundamentalmente una cruda reflexión sobre la maternidad, vista desde un punto estrictamente femenino, casi chocante, muy lejano a las representaciones tradicionales. Márgara Russoto, por su lado, recupera parte de la poética de la brevedad al pretender una poesía limpia, que no exagere sus posibilidades, que no repita sus recursos; asume la cotidianidad como lugar de la experiencia poética. Podría pensarse que los planteamientos de estas poetas son los más interesante de la producción reciente, puesto que además de ofrecer perspectivas inéditas, éstas se realizan en un lenguaje fresco y renovado, o violento y amargo, pero en todo caso también inédito.

Después de los primeros años de la década los poetas de estos grupos, y otros que comulgaban en la misma fe, asumieron caminos más personales; abandonaron en gran medida el lenguaje sentimental, las referencias al mundo callejero, urbano, para situarse en espacios distintos. Un caso interesante es el de la poesía de Yolanda Pantin; su más reciente producción, La canción fría (1991) asume para sí el amor como una experiencia limpia, casi cerebral, lejana al patetismo de otros momentos de su obra. ${ }^{32}$ Igor Barreto, por su lado, asume una reflexión sobre el espacio abierto del campo y sus personajes en Crónicas llanas, (1989); Rafael Arráiz Lucca, Almacén (1988) se detiene en la representación de la memoria. De alguna manera ellos están recorriendo algunos de los caminos que los poetas de los setenta experimentaron, esos a los que se habían opuesto. El caso de Alberto Barrera también puede ser representativo del desplazamiento que sufre esta generación: publica Amor que por demás en 1985, libro en el que aparecen poemas que forman parte de su experiencia con Guaire; en líneas generales ese libro suscribe los lineamientos de la cotidianidad, del lenguaje coloquial, se detiene en la reflexión exteriorista; en él se entiende a la ciudad como espacio lírico. Recientemente publica Edición de lujo, donde reúne una

\footnotetext{
${ }^{31}$ Padrón 76.

${ }^{32}$ Así mismo lo plantea Yolanda Pantin en el epílogo de La canción fría.
} 
serie de poemas en prosa que destilan otro sabor: asume la experiencia de la lectura como espacio para hacer poesía, recurre a una poderosa intertextualidad, maneja referentes primordialmente librescos que se realizan en una forma muy cercana a la de la fábula, pero a la vez se diferencian de ésta por contener sentidos irónicos y desencantadas antimoralejas al estilo del guatemalteco Monterroso. La representación de la experiencia urbana, real, cotidiana, deja lugar a la representación del acto de la lectura, donde sobrevive, eso sí, un lenguaje que no es rebuscado ni intelectual. Su caso no es solitario:

Ya en poetas representativos de la poética predominante durante los ochenta, como Miguel Márquez (desde Soneto al aire libre, 1986), como Yolanda Pantin (sobre todo y de manera tajante en La canción fría, 1989), o como Igor Barreto (en Soy el muchacho más hermoso de la ciudad, 1987) o Rafael Arráiz Lucca (evidentemente en Litoral, 1991), comienza a sentirse una necesidad de alejarse de la insistente precisión realista de la descripción del mundo exterior propio del poeta ... Abundan ya los poemas que tratan sobre ciudades soñadas, nunca vividas sino a través de terceros, por películas o libros o relatos de viajes, ciudades atravesadas por los deseos y los sueños de los que, en el poema, la evocan fantasmalmente." ${ }^{33}$

La experiencia que resultaba para muchos estridente de principios de los ochenta se ve sustituida por otras sensibilidades que recurren espacios cada vez menos familiares al común de los mortales, recurriendo, a veces, a formas interioristas.

Entre las experiencias que expresan el espacio cerrado y mágico de la interioridad del poeta y que se quieren gesto mágico de la individualidad, hasta las experiencias que focalizan su mirada en la calle, en su lenguaje, en las representaciones tradicionales del amor, para luego volver a la meditación y construcción del lenguajes personalizados, la poesía venezolana cuenta con un largo catálogo de poetas que se mueven es un espacio que pareciera breve, que no sale del lugar consagrado a la poesía, que recurre a estrategias muchas veces encantatorias, festivas, mágicas, o cotidianas donde no se encuentra un gran aporte, sólo variaciones suaves.

\section{Bibliografía}

Álvarez, María Auxiliadora. Cuerpo. Caracas: Fundarte, 1985. $\mathrm{Ca}(z) a$. Caracas: Fundarte, 1990.

Arráiz Lucca, Rafael, Armando Coll, Nelson Rivera Prato. Guaire. Caracas: Ediciones del Guaire, 1982.

Balizaje. Caracas: Ediciones del Guaire, 1983.

Terrenos. Caracas: Mandorla, 1985.

Almacén. Caracas: Fundarte, 1988.

Grabados, Libro menor. Caracas: Academia Nacional de la Historia, 1989.

Barrera, Alberto. Amor que por demás. Caracas: Imprenta de Miguel Ángel García, 1985. Edición de lujo. Caracas: Fundarte, 1990.

${ }^{33}$ Castillo Zapata, Amor, Mundo exterior... 2-3. 
Barreto, Igor. Tiempo de ausencia. San Fernando de Apure: Ediciones del Grupo Humo y Tabaco, 1971. ¿Y si el amor no llega? San Fernando de Apure: Ediciones Fundación Rómulo Gallegos, 1983. Soy el muchacho más hermoso de esta ciudad. Caracas: Fundarte, 1987. Crónicas llanas. San Fernando de Apure: Ediciones Sociedad de Amigos del Santo Sepulcro, 1989.

Barroeta, José. Todos han muerto. Caracas: Monte Ávila, 1971. Arte de anochecer. Caracas: Monte Ávila, 1975. Fuerza del dia. Caracas: Ediciones del Ateneo, 1985. Antología. Caracas: Fundarte, 1985. Bohoquez, Douglas. Vagas especies. Caracas: CELARG, 1986.

Castillo Zapata, Rafael. Árbol que crece torcido. Caracas: Ediciones del Guaire, 1984. "Amor, mundo exterior (apuntes apurados para una probable poética de los noventa)". Magazine del Diario de Caracas (7-6-92).

Chacón, Alfredo (ed.). La izquierda cultural venezolana. Caracas: Editorial D. Fuentes, 1970.

Cracco, Laura. Mustia memoria. Mérida: Universidad de los Andes, 1985. Diario de una momia. Maracaibo: Séptimo Sello, 1989.

Crespo, Luis Alberto. Si el verano es dilatado. Mérida: Universidad de los Andes, 1968. Novenario. Caracas: Ediciones de la Universidad Central de Venezuela, 1973. Costumbre de sequía. Caracas: Monte Ávila, 1977. Resolana. Caracas: Monte Ávila, 1980. Entreabierto. Caracas: Monte Ávila, 1984. Señores de la distancia. Caracas: Mandorla, 1988.

Galindo, Elí. Los viajes del barco fantasma. Caracas: Universidad Central de Venezuela, 1974.

Ruido de las esferas. Caracas: Monte Ávila, 1986.

Hernández D’Jesús. Muerto de risa. Caracas: Monte Ávila, 1968. Mi abuelo primaveral y sudoroso. Mérida: Ediciones del Colegio de Abogados, 1974. Asi sea uno de aquí. Caracas: Monte Ávila, 1976. Mi sagrada familia. Mérida: Ediciones de la Universidad de los Andes, 1978. Mi abuelo volvió al fuego. Caracas: Ediciones La Draga y el Dragón, 1980. Retrato en familia. Caracas: Monte Avila, 1988. Recurso del huésped. Caracas: Fundarte, 1988.

Jaffé, Verónica. El arte de la pérdida. Caracas: Ediciones Angria, 1991. Jiménez, Maritza. Hago la muerte. Caracas: Ediciones Con-Texto, 1988.

"Las nuevas promociones literarias tienen la palabra. Mesa redonda". Zona Franca 23 (1981) 4-27.

Liscano, Juan. "Poesía: de 1970 a la actualidad". Zona Franca 30/31 (1982) 8-10.

Liscano, Juan. Panorama de la literatura venezolana actual. Caracas: Alfadil Editores, 1984.

Liscano, Juan. Lecturas de poetas y poesia, Libro menor, 79. Caracas: Academia Nacional de la Historia, 1985. 
León, Eleazar. Precipicio de pájaros. Caracas: Las Formas del Fuego, 1970.

Por lo que tienes de ceniza. Caracas: Ediciones de la Universidad Central de

Venezuela, 1974.

Estación durable. Caracas: Monte Ávila, 1976.

Cruce de caminos. Ediciones de la Universidad Central de Venezuela, 1977.

Palabras del actor en el café de la noche. Caracas: Ediciones del taller Hojas de

Calicanto, 1982.

Márquez, Miguel. Cosas por decir. Caracas: CELARG, 1982.

Soneto al aire libre. Caracas: Fundarte, 1986.

La casa, el paso. Caracas: Monte Ávila, 1991.

Medina, José Ramón. Antología venezolana (verso). Madrid: Gredos, 1962.

Miranda, Julio. Mi voz de veinte años. Granada: Veleta al Sur, 1966.

El libro tonto. Madrid: El Toro de Barro, 1968.

Jaén, la nuit. Jaén: El Olivo, 1970.

No se hagan ilusiones. Caracas: Ediciones Bárbara, 1970.

Tablero. Málaga: El Gudalhorce, 1972.

Maquillando el cadáver de la revolución. Caracas: Fundarte, 1977.

Parapoemas. Caracas: Monte Ávila, 1978.

El poeta invisible. Caracas: Fundarte, 1981.

Vida del otro. Caracas: Con-Textos, 1982.

Anotaciones de otoño. Caracas: Mandorla, 1987.

Rock urbano. Maracaibo: Universidad del Zulia, 1989.

"El poema breve como modelo: Edda Armas". Zona Franca 17 (1980) 14-20.

"La rebelión de las musas" Papel literario de El Nacional (5-1-92).

Montejo, Eugenio. Humano paraiso. Valencia: Clima, 1959.

Elegos. Caracas: Ediciones Arte, 1967.

Muerte y memoria. Valencia: Ediciones de la Universidad de Carabobo, 1972.

Algunas palabras. Caracas: Monte Ávila, 1978.

Trópico absoluto. Barcelona: Laia, 1986.

Nunes, Jorge. Oscilaciones. Caracas: En Haa, 1966. Imágenes y reflejos. Caracas: En Haa, 1967.

Fuego sucesivo. Caracas: Ediciones de la Universidad Central de Venezuela, 1978. Oculto en su memoria. Caracas: Ediciones de la Universidad Central de Venezuela, 1978.

Aproximaciones al roce. Caracas: Ediciones de El Falso Cuaderno, 1980.

- Retratos de arena. Mérida: Gobernación del Estado de Mérida.

Oliveros, Alejandro. Espacios. Valencia: Editorial Central, 1974. El sonido de la casa. Caracas: Monte Ávila, 1984.

Fragmentos I-XXV. Valencia: Ediciones del Consejo Municipal, 1986.

Ortiz, Cecilia. Trébol de la memoria. Caracas: Fundarte, 1978.

La pasión errante. Caracas: Monte Ávila, 1986.

Osuna, William. Mas si yo fuese poeta, un buen poeta. Caracas: CELARG, 1978. Antología de la mala calle. Caracas: Fundarte, 1990.

Ossott, Hanni. Espacios para decir lo mismo. Caracas: Dirección de Cultura de la Universidad Central de Venezuela, 1974. 
Formas en el sueño figuran infinitos. Caracas: Monte Ávila, 1976. Espacios en disolución. Caracas: Gobernación del Distrito Federal, 1976. Espacios de ausencia y de luz. Caracas: Monte Ávila, 1982. Hasta que llegue el día y huyan las sombras. Caracas: Fundarte, 1983. El reino donde la noche se abre. Caracas: Mandorla, 1987.

Padrón Leonardo. Crónicas de la vigilia. (Notas para una poética de los 80). Libro menor. Caracas: Academia Nacional de la Historia, 1990.

Pantin, Yolanda. Casa o lobo. Caracas: Monte Ávila, 1981. Correo del corazón. Caracas: Fundarte, 1985. Poemas del escritor. Caracas: Fundarte, 1989. El cielo de Paris. Caracas: Pequeña Venecia, 1989. La canción fría. Caracas: Ediciones Angria, 1989.

Pérez Oramas, Luis. Salmos (y boleros) de la casa. Caracas: Monte Ávila, 1986.

Pérez-So, Reynaldo. Para morirnos de otro sueño. Caracas: Monte Ávila, 1970. Tanmatra, 1972.

Nuevos poemas. Valencia: Universidad de Carabobo, 1975. 25 poemas. Caracas: Fundarte, 1982. Matadero. Caracas: Amazonia, 1986.

Salas, Alejandro. Coloquio bajo la sombra de un piano. Caracas: CELARG, 1978. Señales de solsticio. Caracas: Ediciones Arte, 1979. Tres. Caracas: Ediciones Arte, 1981. Erotia. Caracas: Mandorla, 1986. Antología comentada de poesía venezolana. Caracas: Alfadil Editores, 1989.

Salas, María Clara. Dibujos en la sombra. Caracas: CELARG, 1978. Linos. Caracas: Fundarte, 1989.

Santaella, Carlos. La lámpara encendida (ensayos). Libro menor 126. Caracas: Academia Nacional de la Historia, 1988. Diez manifiestos literarios venezolanos. Caracas: Casa de Bello, 1986.

Strepponi, Blanca. Poemas visibles. Maracay: Casa de la Cultura de Maracay, 1988. Diario de John Roberson. Caracas: Pequeña Venecia, 1990.

Sucre, Guillermo. La máscara, la transparencia. México: Fondo de Cultura Económica, 1985.

Tenreiro, Salvador. Los sueños fértiles. Caracas: Ediciones de la Universidad Central de Venezuela, 1976. Secreta claridad. Caracas: Talleres de Fotograbado Motta, 1979.

Urdaneta, Antonio. Crebar arbores. Caracas: Monte Ávila, 1983. El milagro de Pablera. Caracas: Ediciones de la Universidad Central de Venezuela, 1989.

Torres, Alicia. Fatal. Caracas: Fundarte, 1989.

Valera Mora, Víctor. Canción del soldado justo. Caracas: Ediciones Luxor, 1961. Amaneci de bala. Mérida: Ediciones Cabimas, 1971. Con un pie en el estribo. Mérida: Ediciones La Draga y el Dragón, 1972. 70 poemas stalinistas. Caracas: Libros Tepuy, 1979. Antología. Caracas: Fundarte, 1987. 
Vargas, Vilma. El devenir de la palabra poética; Venezuela siglo XX. Ediciones de la Biblioteca. Caracas: Universidad Central de Venezuela, 1980.

Vera, Elena. Flor y canto; 25 años de poesía venezolana (1958-1983). Estudios monografías y ensayos, 65. Caracas: Academia Nacional de la Historia, 1985.

Yagüe Jarque, Eloy. Escritores en su tinta. Libro menor. Caracas: Academia Nacional de la Historia, 1991. 